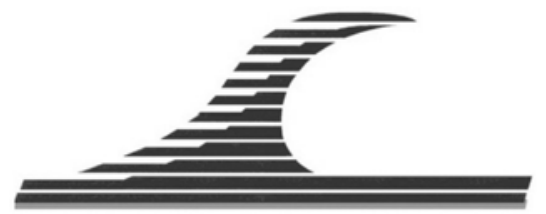

\title{
SHORT NOTE \\ Validation of CFD models for tsunami simulation. TANDEM Project
}

\section{Richard MARCER ${ }^{1}$, Kevin PONS $^{1}$, Camille JOURNEAU ${ }^{1}$, Frédéric GOLAY $^{2}$}

1. Principia S.A.S., Zone Athélia 1, 215 voie Ariane, 13705 La Ciotat cedex, France.

\{ richard.marcer ; kevin.pons ; camille.journeau \}@principia.fr

2. Université de Toulon, IMATH, EA 2134, 83957 La Garde cedex, France.

frederic.golay@univ-tln.fr

\begin{abstract}
:
Into the frame of the TANDEM project (Tsunamis in the Atlantic and the English ChaNnel: Definition of the Effects through numerical Modeling) a first step of the study aims for Principia to qualify different 3D CFD (Computational Fluid Dynamics) models for the simulation of tsunamis. The EOLE code solves a 3D bi-fluid flow on multistructures meshes coupled with a free surface tracking VOF model, whereas the EOLENS code is based on an interface capturing method using unstructured meshes. This paper presents some simulations / measurements comparisons for academic test cases of wave propagation and run-up. On the whole, the results are satisfactory showing the high potential of both codes to simulate tsunamis impact.
\end{abstract}




\section{Introduction}

The TANDEM project aims to evaluate the impact of a tsunami on French coastal industrial infrastructures. A first step of this project is dedicated to the validation of CFD models on academic test-cases of wave propagation and impact on structures (PONS et al., 2015). The two test cases presented in this paper dispose of experimental data allowing the qualification of the numerical models. The first concerns the breaking and the run-up of a tsunami wave on a constant slope. The second shows the impact of a tsunami on a coastal urban site.

The numerical models used in this project are the two CFD multiphase EOLE and EOLENS codes developed by Principia and the Institut de Mathématiques de Toulon. After a brief presentation of the models, the paper presents for both cases the comparisons between the numerical results and the experimental data.

\section{Presentation of the CFD models}

\subsection{EOLE model}

The EOLE code developed by Principia since 1990 is a multi-phase URANS model solving the equations on structured curvilinear multi-blocks meshes (possibly moving and deforming). It is based on a pseudo-compressibility technic using a dual time stepping and a second order finite volume scheme for spatial discretization. The motion of the interface between the different phases is simulated from an implicit VOF model avoiding any CFL constraint. The transport of the VOF function (actually the displacement of the interface) may be ensured by a classical eulerian equation or by an improved eulerian-lagrangian method developed by Principia (GUIGNARD et al., 2001; BIAUSSER et al., 2004).

\subsection{EOLENS model}

The EOLENS code solves the 3D bi-fluid Euler equations on unstructured meshes, from a finite volume method. The incompressibility condition is relaxed from a low Mach approach (GOLAY \& HELLUY, 2007). For isothermal cases the pressure is explicitly computed via an artificial law of the state reducing the CFL constraint. Contrary to the EOLE code, this model is not based on a reconstruction technic for the interface modelling, leading to interface diffusion for relative long simulation. This default can be reduced with the use of an interface compression method (SAMBE, 2011).

\section{Breaking of a tsunami wave on a constant slope (1/15)}

The experiment has been carried out at the California Institute of Technology (CAMFIELD et al., 1998). The available data concern the evolution of the interface of the plunging wave at different instants. In the numerical models, the wave is initialized with a Boussinesq solution, with the wave amplitude $(A)=0.45 \mathrm{~h}$ and $\mathrm{h}$ the depth of the 
channel. Figure 1 shows an example of a plunging wave simulated with the two codes. Figure 2 gives comparisons of the wave interface at different instants.

Results obtained are satisfactory on the whole. Both codes EOLE and EOLENS allow to capture the complex physics of the wave breaking up to the splash phenomenon.
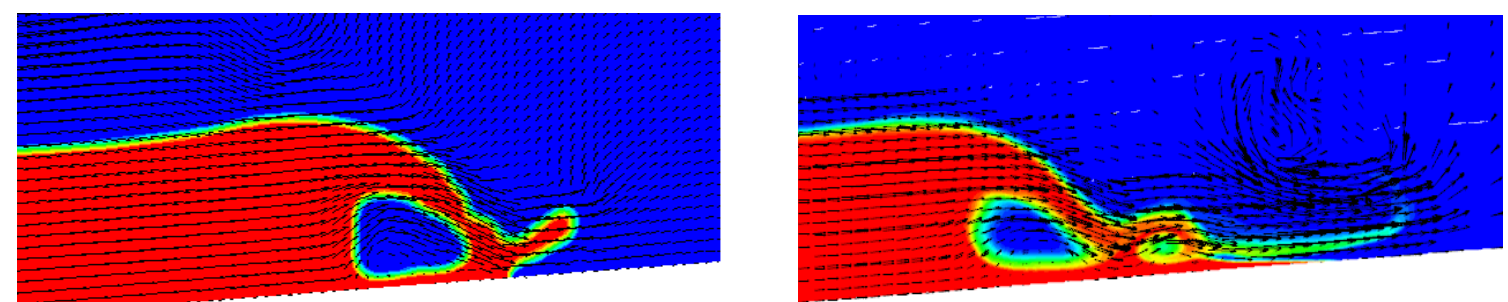

Figure 1. CFD simulation of wave breaking - EOLE (left) and EOLENS (right).

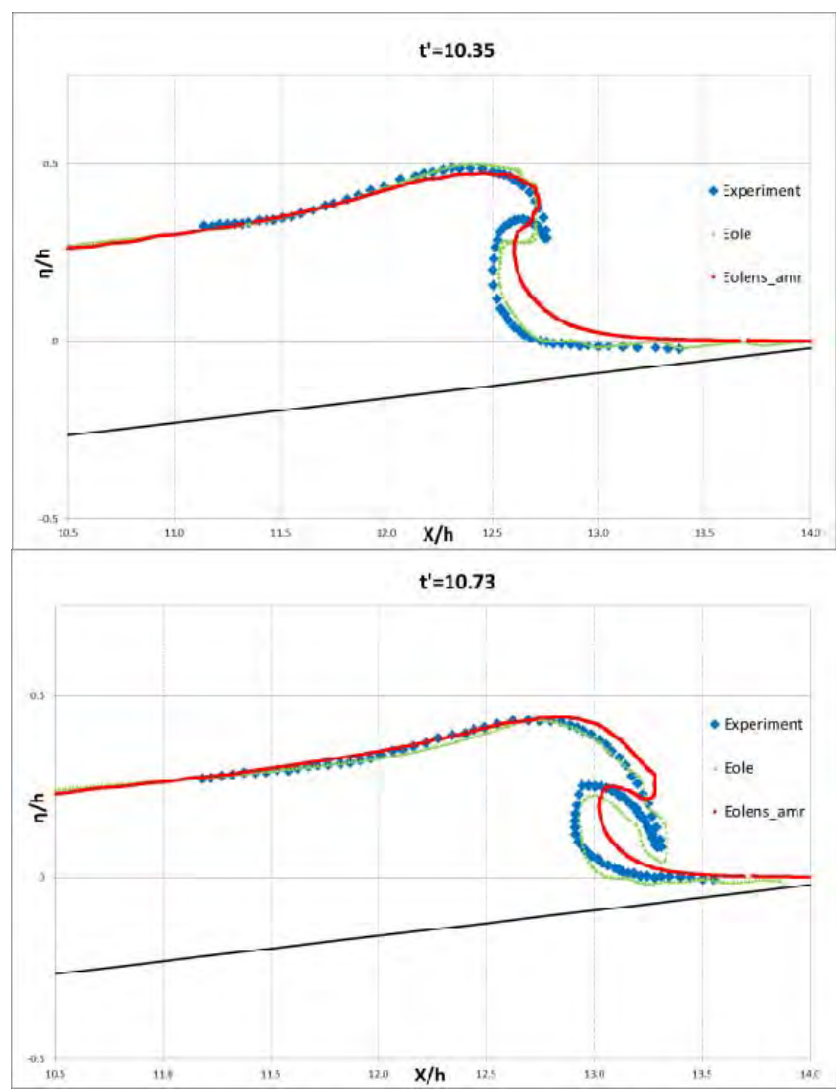

Figure 2. Wave shape at different instants- EOLE (green) - EOLENS (red).

\section{Impact of a tsunami on a coastal city}

The experimental model represents the Seaside city (Oregon USA) at 1/50 scale (PARK et al., 2013) including many buildings of various sizes. Elevation probes (31) are placed mostly in the city at different positions between buildings (figure 3). The wave has an amplitude of $0.2 \mathrm{~m}$ with a water depth of $1 \mathrm{~m}$. The simulation is done with the EOLE code. Figure 4 shows an example of visualization of the wave impacting the city. 
n04.4 : Revue Paralia - Vol. 8 (2015)

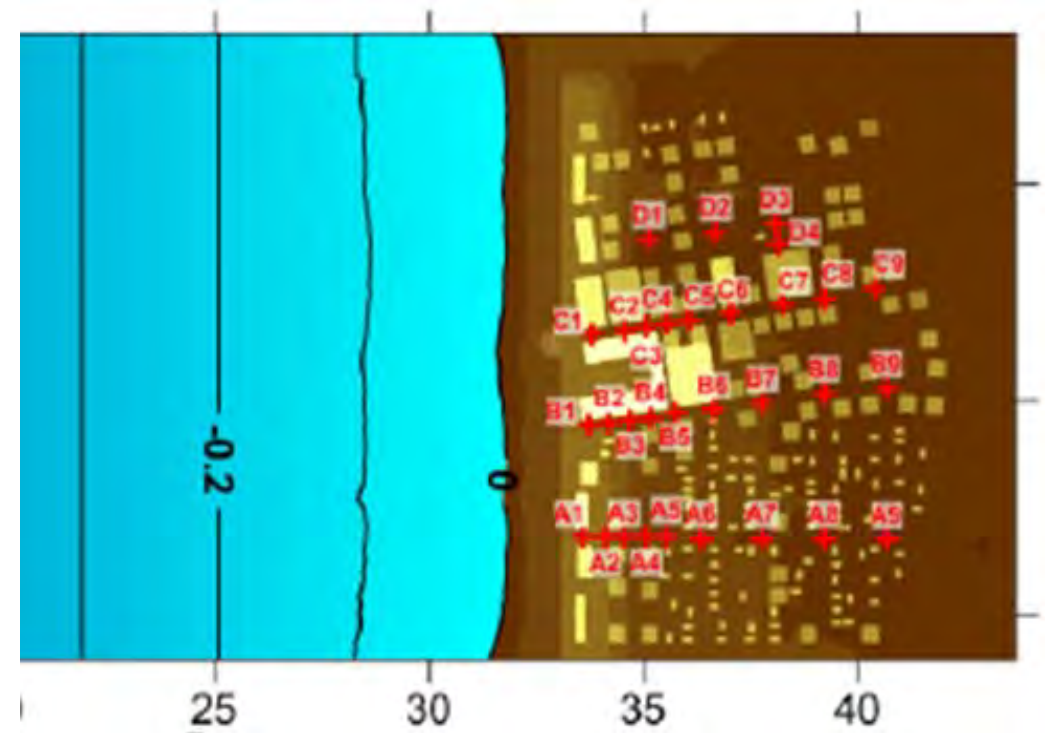

Figure 3. Experimental model of the city and positions of the elevation probes.

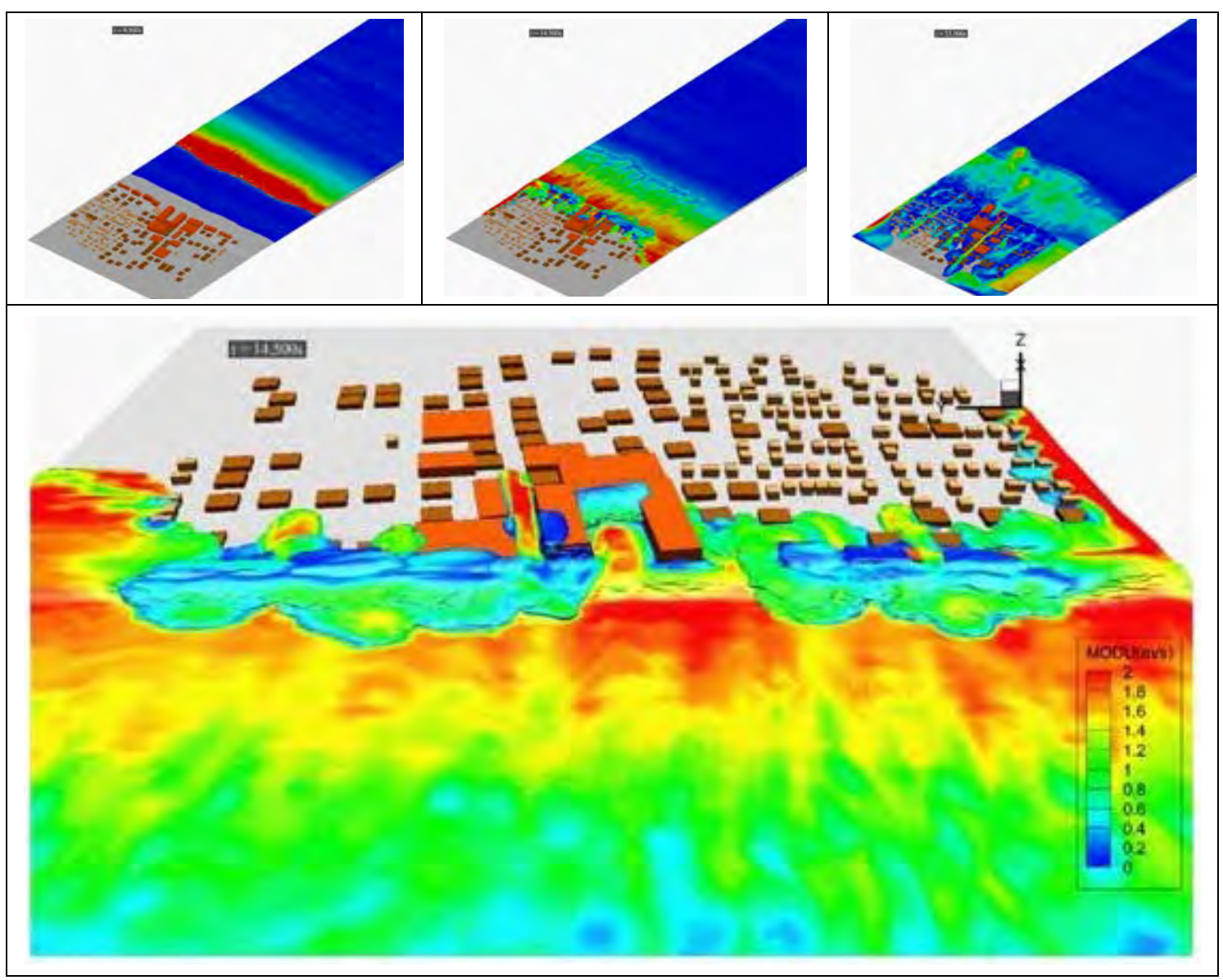

Figure 4. Simulation with EOLE of a tsunami impacting a coastal city. 


\section{Conclusions}

Some extracts of results shown in this paper demonstrate the ability of both codes to simulate the impact of a tsunami on a coastal site. Additional validations on academic tests are ongoing, allowing to reinforce the validity domain of both softwares. Within the framework of the TANDEM project it is then foreseen to qualify these codes for the simulation of the Tohuku-oki event in Japan in 2011.

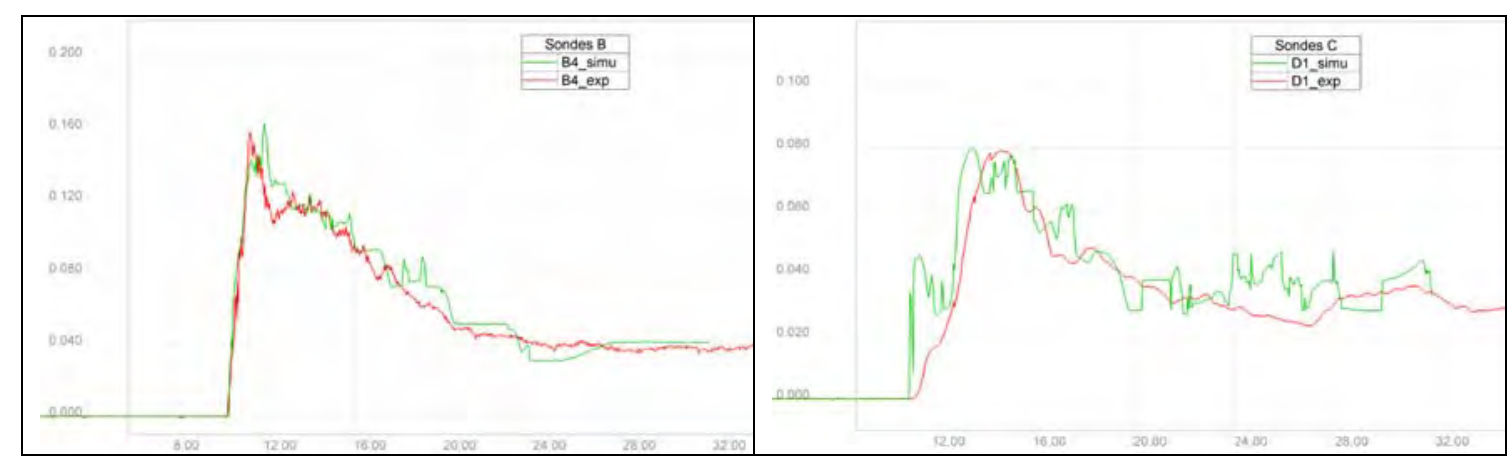

Figure 5. Example of comparisons of the wave elevation on probes B4 (left) and D1 (right) - EOLE in green - Experiments in red.

\section{Aknowledgments}

TANDEM = Tsunamis in the Atlantic and the English ChaNnel et MaNche: Definition of the Effects through numerical Modeling (2014-2018): a French initiative to improve tsunami hazard assessment in France.

TANDEM is supported through the French PIA grant ANR-11-RSNR-00023 of the program Recherches en matière de Sûreté Nucléaire et Radioprotection.

The authors would like to thank P. L. Hugues for his active support.

\section{References}

BIAUSSER B., MARCER R., GUIGNARD S., FRAUNIE P. (2004). 3-D two phase flows numerical simulations by SL-VOF method, Int. J. For Num. Meth. Fluids, Vol. 45, pp 581-604. http://dx.doi.org/10.1002/fld.708

GUIGNARD S., MARCER R., REY V., KHARIF C., FRAUNIE P. (2001). Solitary wave breaking on sloping beaches: $2 D$ two phase flow numerical simulation by $S L-V O F$ method, Eur. J. Mech. B, Fluids, Vol. 20, pp 57-74. http://dx.doi.org/10.1016/s09977546(00)01104-3

GOLAY F., HELLUY P. (2007). Numerical schemes for low Mach wave breaking, International Journal of Computational Fluid Dynamics, Vol. 21(2), pp 69-86. http://dx.doi.org/10.1080/10618560701343382 
CAMFIELD F., LI Y., RAICHLEN F., GRILLI S., SVENDSEN I., SUBRAMANYA R. (1998). Discussions and Closure: Breaking Criterion and Characteristics for Solitary Waves on Slopes. J. Waterway, Port, Coastal, Ocean Eng., Vol. 124(6), pp 329-333. http://dx.doi.org/10.1061/(ASCE)0733-950X(1998)124:6(329)

PARK H., COX D.T., LYNETT P.J., WIEBE D.M., SHIN S. (2013), Tsunami inundation modeling in constructed environments: A physical and numerical comparison of free-surface elevation, velocity, and momentum flux, Coastal Engineering, Vol. 79, pp 9-21. http://dx.doi.org/10.1016/j.coastaleng.2013.04.002

PONS K., JOURNEAU C., MARCER R., GOLAY F. (2015), Calculs CFD de propagation et d'impact de vague en zone côtière, 33èmes Rencontres de l'AUGC, ISABTP/UPPA, Anglet, France, 27-29 May 2015.

SAMBE A.N. (2011). Développement d'un modèle de simulation 3D d'impact de vagues en zones côtières et offshores, Thèse de doctorat, Université de Toulon. 